\title{
Loneliness and Attitudes toward Aloneness in Belgian Adolescents: Measurement Invariance across Language, Age, and Gender Groups
}

\author{
Sofie Danneel ${ }^{1} \cdot$ Marlies Maes $^{1} \cdot$ Patricia Bijttebier $^{1} \cdot$ Marianne Rotsaert $^{2} \cdot$ Marie Delhaye $^{2} \cdot$ Tara Berenbaum $^{2}$. \\ Luc Goossens ${ }^{1}$
}

(C) Springer Science+Business Media, LLC, part of Springer Nature 2018

\begin{abstract}
In this study, the factor structure and psychometric properties of a French adaptation of the well-established Loneliness and Aloneness Scale for Children and Adolescents (LACA) was investigated in a French-speaking sample of Belgian adolescents $(N=641$; Mage $=14.35, \mathrm{SD}=2.03 ; 53.4 \%$ girls $)$. In addition, measurement invariance analyses across the two main language groups in Belgium (i.e., Dutch-speaking and French-speaking) and across age and gender were conducted on a combined sample of French-speaking and Dutch-speaking Belgian adolescents $(N=1282$; Mage $=14.36$ years, SD = 2.03; 53.6\% female). Subsequently, group mean differences across language, age, and gender groups were investigated. Convincing support was found for the expected four-factor structure of the French adaptation of the LACA and the measure showed good reliability. Results further indicated that Belgian adolescents from the two principal language groups and from different age and gender groups interpreted the items of the LACA similarly. Therefore, analyses of group mean differences could be compared. Given the small effect sizes that accompanied the obtained effects, replication research is needed to further investigate these group mean differences.
\end{abstract}

Keywords Loneliness $\cdot$ Attitudes toward aloneness $\cdot$ Measurement invariance $\cdot$ Regional differences $\cdot$ Belgium

Loneliness is "the unpleasant experience that occurs when a person's network of social relations is deficient in some important way, either quantitatively or qualitatively" (Perlman and Peplau 1981, p. 31). Loneliness is a universal phenomenon that occurs throughout the lifespan, but is particularly salient during adolescence (Qualter et al. 2015). More specifically, loneliness in the relationships with peers and with parents tends to peak during adolescence (Marcoen and Goossens 1993). Adolescents are typically confronted with numerous changes in their social world, such as a more pronounced

Electronic supplementary material The online version of this article (https://doi.org/10.1007/s10862-018-9671-9) contains supplementary material, which is available to authorized users.

Sofie Danneel

sofie.danneel@kuleuven.be

1 School Psychology and Development in Context Research Group, KU Leuven, Tiensestraat 102 box 3717, 3000 Leuven, Belgium

2 Laboratory of Psychiatric Research, Hospital Erasmus, Université Libre de Bruxelles, Route de Lennik 808, CP575, 1070 Bruxelles, Belgium preoccupation with their social status and higher expectations about social relationships in the peer realm, and greater autonomy in their relationship with their parents (Heinrich and Gullone 2006; Laursen and Hartl 2013). These changes make adolescents highly vulnerable to experiencing feelings of loneliness, which in turn is associated with several negative mental and physical health problems (Heinrich and Gullone 2006).

Aloneness is the objective experience of being without company (Long and Averill 2003) and is not the same as loneliness. One can feel lonely when alone but also when surrounded by people. From early adolescence onwards, young people spend a greater amount of time alone and their experience of being alone changes substantially (Larson 1997; Larson and Richards 1991). Aloneness emerges as a constructive domain of experience in adolescents' life, represented by a positive association between time spent alone and adolescents' well-being (Larson 1997). In addition, adolescents may have more or less positive or negative attitudes toward aloneness. These attitudes toward aloneness may function as moderators in the relationship between aloneness and feelings of loneliness. For example, adolescents who spend a lot of time alone, but have negative 
attitudes toward aloneness, may be more likely to experience feelings of loneliness (Goossens 2016).

\section{A Multidimensional Measure to Assess Loneliness and Attitudes toward Aloneness}

The Loneliness and Aloneness Scale for Children and Adolescents (LACA; Marcoen et al. 1987) is a frequently used questionnaire that builds on a hybrid multidimensional model of loneliness (Marcoen et al. 1987). According to this model, loneliness can take on multiple forms and varies in intensity and function across relationships (Goossens et al. 2009; Majorano et al. 2015). The LACA measures two types of loneliness, that is, parent-related loneliness and peer-related loneliness, and two attitudes toward aloneness, that is, positive and negative attitudes. It was originally developed in Belgium for use with Dutch-speaking adolescents from ages 10 to 19 (Marcoen et al. 1987). The psychometric properties of this Dutch version of the LACA are well-established (Goossens 2016). For example, convincing support has been found for the supposed four-factor structure of the LACA (Maes et al. 2015a). In addition, the Dutch version of the LACA shows good reliability (Maes et al. 2015b) and shows measurement invariance across age and gender (Maes et al. 2015a).

The LACA is not only available in Dutch, but has been translated into numerous other languages as well (i.e., Arabic, Chinese, English, Greek, Hebrew, Italian, Spanish, and Portuguese; Maes 2016). However, until now, a French version of the LACA was lacking.

Because French is an important language in several countries, there was a clear need to translate the LACA for use with French-speaking adolescents. More specifically, French is an important language in France, Switzerland, and Canada, but also in Belgium, where the two principal languages are Dutch (used by approximately $60 \%$ of the Belgian population) and French (used by approximately $40 \%$ of the Belgian population; European Commission 2005). By establishing a French version of the LACA in addition to the already existing Dutch version, regional differences in loneliness and attitudes toward aloneness across Belgium can be investigated. However, before meaningful comparisons across regions can be made, one should establish measurement invariance (Chen 2007; van de Schoot et al. 2012).

\section{Language, Age, and Gender Differences in Loneliness and Attitudes toward Aloneness}

Until now, research about differences in loneliness and attitudes toward aloneness in the two linguistic regions in Belgium has been lacking. A limited number of studies has investigated regional differences in the prevalence of internalizing problems in Belgium. More specifically, research on generalized anxiety disorder and major depression in patients in primary care in Belgium indicated that the prevalence of these disorders is much higher in the French-speaking part of Belgium, compared to the Dutch-speaking part of Belgium (Ansseau et al. 2005, 2008). These results continued to be significant when controlling for socioeconomic differences. However, explanations for these regional differences remain unclear. Given that there are regional differences in the prevalence of other internalizing problems in Belgium, it might be possible that adolescents from the Frenchand Dutch-speaking part of Belgium also differ in their mean loneliness levels.

Using the LACA with both language groups will further allow us to examine whether age and gender differences in loneliness and attitudes toward aloneness take on a similar form in Dutch-speaking and French-speaking adolescents in Belgium. Regarding age differences in loneliness and attitudes toward aloneness, theoretical notions suggest an increase in parent-related loneliness and positive attitudes toward aloneness and a decrease in peer-related loneliness and negative attitudes toward aloneness (Marcoen and Goossens 1993; Marcoen et al. 1987). Parent-related loneliness is expected to increase as a result of diminished parental attention accompanied by a continued need for parental guidance throughout adolescence. Peer-related loneliness is expected to decrease because of adolescents' increased capacity and need for relational intimacy (Marcoen and Goossens 1993). In addition, positive and negative attitudes toward aloneness are expected to increase and decrease, respectively, because adolescents spend an increasing amount of time alone and use this time alone in a more constructive way (Larson 1997; Larson and Richards 1991). However, earlier cross-sectional studies regarding age differences in loneliness and attitudes toward aloneness yielded inconsistent results. Given that earlier studies failed to consistently confirm these theoretical expectations, age differences in loneliness and attitudes toward aloneness remain unclear. In addition, longitudinal research on the developmental trends of loneliness and attitudes toward aloneness is scarce and has focused mainly on peer-related loneliness (Ladd and Ettekal 2013; van Roekel et al. 2010).

Regarding gender differences in peer- and parent-related loneliness, a recent meta-analysis found no gender differences in loneliness in children and adolescents (Maes et al. 2017). This finding is in line with the evolutionary theory of loneliness (Cacioppo et al. 2006), which considers loneliness as a universal, biologically inherited warning system that signals to both males and females when their universal need to belong (Baumeister and Leary 1995) is not being met. In contrast, less is known about gender differences in attitudes toward aloneness. The limited number of studies on this topic showed inconsistent results. Some studies, for example, reported no gender differences for positive attitudes toward aloneness in 
adolescence (Goossens 2016), whereas others reported that adolescent girls are more positive towards aloneness than boys (Corsano et al. 2006; Goossens and Marcoen 1999; Scharf et al. 2011). Regarding negative attitudes toward aloneness, some studies found no gender differences (Goossens and Marcoen 1999; Scharf et al. 2011), whereas others found more negative attitudes toward aloneness in adolescent girls (Maes et al. 2015a). These inconsistent results and the lack of a clear theory indicate the need for more research regarding gender differences in attitudes toward aloneness.

\section{The Current Study}

The current empirical effort had three objectives. First, this study sought to investigate the factor structure and psychometric properties of a French version of the LACA. We expected that the French version of the LACA would have a four-factor structure comparable to the four-factor structure of the Dutch version of the LACA. Second, this study aimed to investigate whether adolescents from the two main language groups in Belgium (i.e., Dutch and French), the two genders, and different age groups interpreted the LACA items in a similar way by conducting measurement invariance analyses. Third, if the LACA showed measurement invariance across language, gender, and age groups, this study aimed to investigate whether adolescents from Belgium's main linguistic regions differed in their experiences of loneliness and their attitudes toward aloneness, whether there were age and gender differences in loneliness and attitudes toward aloneness in Belgian adolescents, and whether these age and gender differences took on a different form in the two linguistic regions. Because no studies have investigated regional differences in loneliness in Belgium, our analyses regarding the regional differences in reported feelings of loneliness and attitudes toward aloneness among Belgian adolescents were exploratory in nature. Regarding age differences, theoretical notions suggest an increase in parent-related loneliness and positive attitudes toward aloneness and a decrease in peer-related loneliness and negative attitudes toward aloneness. However, given that the results of previous studies were inconsistent, we only expected small age differences in line with the theoretical notions in both the French-speaking and Dutch-speaking sample. Concerning gender differences in loneliness, based on the results of a meta-analysis on gender differences and in line with the evolutionary theory of loneliness, we expected no gender differences in Belgian adolescents. Finally, given the lack of a clear theory regarding gender differences in attitudes toward aloneness and given that results of earlier studies were inconsistent, our analyses on this topic were purely exploratory.

\section{Method}

\section{Participants and Procedure}

This study used two samples of adolescents from the two main linguistic regions in Belgium, that is, the French-speaking and the Dutch-speaking region. Regarding the French-speaking sample, in a first step, four secondary schools offering the academic track were invited to participate in a study on the development of a French version of the LACA. Two schools, a governmental and a non-governmental school were willing to participate. The participating schools were located in the city center of Brussels, the capital city of Belgium, and a suburb of Brussels, respectively. The first city quarter is generally regarded as economically deprived and the second one as affluent.

Adolescents from Grades $7\left(M_{\text {age }}=11.95\right.$ years, $\left.S D=0.58\right)$ through $12\left(M_{\mathrm{age}}=17.16\right.$ years, $\left.S D=0.78\right)$ were invited to participate. A total of 644 adolescents participated in the study. Three adolescents were dropped from the current analyses because they had more than two-thirds of missing data on one or more subscales. The final French-speaking sample consisted of 641 adolescents $\left(M_{\text {age }}=14.35\right.$ years, $S D=$ 2.03 ), of whom $53.4 \%$ were girls. The majority of adolescents in this sample were born in Belgium (80,5\%) and lived with both of their parents $(63.8 \%)$. Only $2.3 \%$ of the data was missing. Little's MCAR Test (Little 1988) was significant, but the normed chi square was acceptable (i.e., $\chi 2 /$ $d f<2$; Ulman 2013) indicating that the data were missing completely at random. Therefore, missing values could be imputed by means of the ExpectationMaximization procedure in SPSS 24.0.

The Dutch-speaking sample was drawn from a much larger data set $(N=9676)$ by means of a matching procedure. More specifically, for every French-speaking participant, a one-byone match was drawn from the larger Dutch-speaking sample based on age and gender. This matching procedure resulted in a sample of 641 Dutch-speaking adolescents $\left(M_{\text {age }}=\right.$ 14.36 years, $S D=2.03 ; 53.7 \%$ girls). The French-speaking and Dutch-speaking sample did not differ significantly from one another in terms of average age $(t(1277)=-0.04, p=.97)$ or the percentage of female adolescents $\left(\chi^{2}=0.00, p=.98\right)$. All participating adolescents in the Dutch-speaking sample were following the academic track. No additional background information of the Dutch-speaking sample was available. Because none of the Dutch-speaking adolescents had more than two-thirds of missing data on one or more subscales, none of the participants were dropped from the current analyses. Only $0.23 \%$ of the data was missing. In addition, Little's MCAR Test (Little 1988) was non-significant and the normed chi square was acceptable (i.e., $\chi 2 / d f<2$; Ulman 2013) indicating that the data were missing completely at random. 
Therefore, missing values could be imputed by means of the Expectation-Maximization procedure in SPSS 24.0.

Both samples were combined into a single sample of Belgian adolescents $\left(N=1282 ; M_{\mathrm{age}}=14.36, S D=2.03\right.$, $53.6 \%$ female). To investigate measurement invariance across age, three different age groups were created. The early adolescent group contained Belgian adolescents with ages ranging from 11 to 13 years $(n=489 ; 54 \%$ girls). The middle adolescent group comprised Belgian adolescents aged 14 to 16 years $(n=553 ; 52.1 \%$ girls) and the late adolescent group contained Belgian adolescents aged 17 to 20 years $(n=$ 237; 55.3\% girls). These three age groups represent the three phases of development in adolescence (WHO 2014; Clark-Lempers et al. 1991).

Permission for the data collection in the French sample was obtained in 2015 from the ethical committee of the Erasmus Hospital in Brussels, the capital city of Belgium. The large Dutch dataset, from which a random sample was drawn for this study, results from an integration of different studies that took place between 1993 and 2003 (Goossens 2016). Data collection conformed to the ethical standards that were held during that time period. In both regions, active informed consent was obtained from the participating adolescents prior to data collection. Adolescents filled out the LACA at school during regular school hours. A research assistant or master student in psychology was present to introduce the study and to answer questions when needed. The voluntary and anonymous character of the participation was emphasized. In addition, adolescents were informed that they could discontinue their participation at any time, but none of them opted to do so.

\section{Measure}

Loneliness and attitudes toward aloneness were assessed using the multidimensional Loneliness and Aloneness Scale for Children and Adolescents (LACA; Marcoen et al. 1987). The LACA consists of 48 items which are equally divided over four subscales. Those subscales measure (a) loneliness in relation to parents (12 items, e.g., "I feel left out by my parents"), (b) loneliness in relation to peers (12 items, e.g., "I feel left out by my friends", (c) negative attitudes toward aloneness (12 items, e.g., "When I am alone, I feel bad"), and (d) positive attitudes toward aloneness (12 items, e.g., "I want to be alone"). Participants were asked to respond to the items on a Likert scale ranging from (1) 'never' to (4) 'often'. Higher mean scores represent greater loneliness and more pronounced negative or positive attitudes toward aloneness, respectively. The reliability and validity of the Dutch-language version of the LACA are well-established (Goossens 2016; Maes et al. 2015b).

The LACA was translated into French by means of a committee approach (Furukawa et al. 2014). Two native French speakers, one from the Université Libre de Bruxelles (ULB) and another one from the Université de Liège, and a Dutchspeaking expert in loneliness who co-developed the original LACA, all Belgian nationals, translated the items of the Dutch version of the LACA into French. These translations were compared and refined by the committee until a consensus was reached. The final French version of the LACA is included as an appendix at the end of this manuscript.

\section{Plan of Analysis}

First, we examined the dimensionality of the French version of the LACA by running several confirmatory factor analyses (CFA) in Mplus Version 7.31 (Muthén and Muthén 19982012) using the robust Maximum Likelihood estimator (MLR) to account for non-normality. First, a single-factor model was tested. Second, we tested a model with two factors to see whether we could distinguish a loneliness and an attitude toward aloneness factor. Third, a three-factor model comprising a general attitude toward aloneness factor and the two types of loneliness as separate factors, that is, parent-related and peer-related loneliness, was examined. Fourth, a threefactor model consisting of a general loneliness factor, a positive attitude toward aloneness factor, and a negative attitude toward aloneness factor was tested. Fifth, a four-factor model comprising loneliness in relationship with parents and peers, and positive and negative attitudes toward aloneness was evaluated.

The different models were evaluated by means of several fit indices. Chi-square statistics $\left(\chi^{2}\right)$, among which the Satorra-Bentler scaled chi-square statistic ( $\mathrm{S}-\mathrm{B} \chi 2$; Satorra and Bentler 2001), are recommended when reporting on model fit (Hayduk et al. 2007; Vandenberg and Lance 2000). Nevertheless, an important limitation of this index is its high sensitivity to sample size. When large samples are used, the $\chi^{2}$-statistic will easily be significant, suggesting a rejection of the model (Barrett 2007). Therefore, it is important to consider other fit indices as well, that is, the normed Chi-square statistic $\left(\chi^{2} / \mathrm{df}\right)$, the Root Mean Square Error of Approximation (RMSEA), the Standardized Root Mean Square Residual (SRMR), and the Comparative Fit Index (CFI) (Boomsma 2000). There is no clear consensus regarding an acceptable ratio for the normed chi-square statistic. Values below 2 or 3 (Ulman 2013) up to below 5 (Schumacker and Lomax 2004) are suggested as reflecting acceptable fit. According to the guidelines of $\mathrm{Hu}$ and Bentler (1999), a model shows good fit when the RMSEA and SRMR are lower than .06 and .08, respectively, and the CFI exceeds .95. In addition, the Akaike Information Criterion (AIC) and Bayesian Information Criterion (BIC) were used to compare the different models, with a lower AIC/BIC value indicating a better trade-off between model fit and complexity (Kline 2005; Neath and Cavanaugh 2012; van de Schoot et al. 2012). 
Second, we conducted measurement invariance analyses across the language, age, and gender groups. In these analyses, we investigated whether the LACA items are interpreted in a similar way by Belgium's two main language groups, by boys and girls, and by early, middle, and late adolescents. A first step in all measurement invariance analyses implied that the model that was retained in the first step of the analysis was tested in all groups separately and its model fit evaluated to determine whether configural invariance was established (van de Schoot et al. 2012). Subsequently, configural, metric, and scalar invariance were tested in the multigroup sample. To test for metric invariance, the fit of a multigroup model without any constraints (i.e., the configural model) was compared to a multigroup model with factor loadings constrained to be equal in both groups (i.e., the metric model). Scalar invariance was examined by comparing the metric model with a model in which both the factor loadings and intercepts were constrained to be equal across language, age, or gender groups (i.e., the scalar model).

Metric invariance was evaluated by comparing three fit indices, that is, CFI, SRMR, and RMSEA of the configural model with the same fit indices of the metric model. According to the guidelines of Chen (2007), a difference in CFI equal to or more than -.010 , accompanied by a change in SRMR or RMSEA equal to or above .030 and .015 , respectively, indicates metric noninvariance. Scalar invariance, in turn, was evaluated by calculating the differences in fit indices between the metric and scalar model. A difference in CFI equal to or above -.010 , accompanied by a difference in SRMR or RMSEA equal to or above .010 , and .015 , respectively, indicates scalar noninvariance.

Third, if scalar invariance could be established, group mean differences were examined in SPSS 24.0 by means of multivariate analyses of variance (MANOVAs) and subsequent analyses of variance (ANOVAs) for each subscale separately. Significant ANOVAs were followed up by means of post-hoc comparisons based on Tukey HSD tests. Significant effects were evaluated using a Benjamini-Hochberg adjusted alpha value of .03 to control for multiple testing (Benjamini and Hochberg 1995).
Because analyses based on a large number of items can lead to overly complex models (Little et al. 2002), we used the item-to-construct balance (ICB) parceling method in all confirmatory factor analyses and measurement invariance analyses. By creating parcels, individual items are aggregated into a combined score. As a consequence, the number of indicators determining a latent factor decreases. This approach has the advantage of model parsimony and is also supposed to be more realistic and to result in more representative results than the use of individual items (Little et al. 2002; Rushton et al. 1983). Because the optimal number of parcels is three (Little et al. 2002; Matsunaga 2008), we created three parcels each consisting of four items for each subscale of the LACA.

\section{Results}

\section{Psychometric Properties and Dimensionality of the French LACA}

Fit indices for the different models examined in the Frenchspeaking sample are represented in Table 1. Based on the rules of thumb of $\mathrm{Hu}$ and Bentler (1999) and the fact that the AIC and BIC values for the final model were lower than the respective values for all other models, we concluded that only the four-factor model showed a good fit to the data.

Correlations among the subscales and Cronbach's alphas for both samples are represented in Table 2. All of the values obtained were very similar across the linguistic groups. According to the benchmarks proposed by Cohen (1988), low correlations (i.e., $r<.30$ ) were found among the four expected subscales, except for a moderate correlation between peer-related loneliness and positive attitude toward aloneness. Using the criteria proposed by De Vellis (2003), all four subscales had a good internal consistency (i.e., Cronbach's alpha $\geq .80$ ).

Table 1 Fit indices for various factor models (French-speaking sample)

\begin{tabular}{|c|c|c|c|c|c|c|c|c|c|}
\hline Model & Number of Factors & Description & $x^{2}$ & $d f$ & CFI & RMSEA & SRMR & AIC & $\mathrm{BIC}$ \\
\hline 1 & 1 & No distinctive subscales & $2035.17 * * *$ & 54 & .39 & .24 & .18 & $12,599.39$ & $12,760.06$ \\
\hline 2 & 2 & Parent+peer/negative+positive & $1629.60 * * *$ & 53 & .52 & .22 & .19 & $12,153.44$ & $12,318.57$ \\
\hline 3 & 3 & Parent+peer/negative/positive & $1360.50 * * *$ & 51 & .60 & .20 & .16 & $11,830.54$ & $12,004.60$ \\
\hline 4 & 3 & Parent/peer/negative+positive & $885.53 * * *$ & 51 & .69 & .18 & .16 & $11,365.95$ & $11,540.01$ \\
\hline 5 & 4 & Four distinct subscales & $126.98 * * *$ & 48 & .98 & .05 & .04 & $10,563.89$ & $10,751.34$ \\
\hline
\end{tabular}

CFI Comparative fit index, RMSEA Root mean square error of approximation, SRMR Standardized root mean squared residual, AIC Akaike information criterion, $B I C$ Bayesian information criterion

$* * * p<.001$ 
Table 2 Intercorrelations among subscales and reliability (Cronbach's alpha)

\begin{tabular}{lllll}
\hline Subscale & 2. & 3. & 4. & $\alpha$ \\
\hline French-speaking Sample & & & & \\
$\quad$ Peer-related loneliness & $.14^{* *}$ & $.37^{* *}$ & $.19^{* *}$ & .83 \\
$\quad$ Parent-related loneliness & - & $.19^{* *}$ & .03 & .86 \\
$\quad$ Positive attitude toward aloneness & & - & .03 & .80 \\
$\quad$ Negative attitude toward aloneness & & & - & .83 \\
Dutch-speaking Sample & & & & \\
$\quad$ Peer-related loneliness & $.13^{* * *}$ & $.36^{* *}$ & $.09 *$ & .90 \\
$\quad$ Parent-related loneliness & - & .07 & .06 & .91 \\
$\quad$ Positive attitude toward aloneness & & - & -.06 & .85 \\
$\quad$ Negative attitude toward aloneness & & & - & .80 \\
\hline$* p<.05 . * * p<.01$ & & & &
\end{tabular}

\section{Measurement Invariance across Language, Age, and Gender Groups}

First, results on configural invariance across groups are represented in Table 3. This type of invariance was established in the two language groups and in the different gender and age groups. In other words, the expected four-factor structure of the LACA fitted the data well in all of these groups separately.

Second, measurement invariance analyses were conducted to investigate configural, metric, and scalar invariance across groups and the results are represented in Table 4. The LACA showed configural, metric, and scalar invariance across language, age, and gender groups. Scalar invariance indicates that the items of the LACA have the same unit of measurement and the same intercept in the different groups. In other words, all of these groups interpreted the items in a similar way (Chen 2007; van de Schoot et al. 2012).

\section{Mean Differences in Language Groups, Age, and Gender}

First, it is important to note that the effect sizes of the main and interaction effects of both the MANOVA and subsequent ANOVAs were all rather small $\left(\eta^{2}\right.$ partial ranging between .001 and .06). This might raises questions regarding the practical relevance of the significant effects described below.

Results of a 2 (Gender) $\times 2$ (Language group) $\times 3$ (Age) MANOVA showed significant main effects for language group $\left(F(4,1261)=25.44, p<.001, \eta_{\text {partial }}^{2}=.08\right)$, gender $\left(F(4,1261)=3.34, p=.01, \eta_{\text {partial }}^{2}=.01\right)$, and age $(F(8$, $\left.2524)=15.59, p<.001, \eta_{\text {partial }}^{2}=.05\right)$. In addition, a significant Language group $\mathrm{x}$ Gender interaction effect was found $(F$ $\left.(4,1261)=2.74, p<.03, \eta_{\text {partial }}^{2}=.01\right)$. The Language group $\mathrm{x}$ Age $\left(F(8,2524)=1.09, p>.05, \eta_{\text {partial }}^{2}<.001\right)$ and Age $\mathrm{x}$ Gender $\left(F(8,2524)=0.94, p>.05, \eta_{\text {partial }}^{2}<.001\right)$ interactions were not significant. In addition, no significant three-way interaction effect (i.e., Language group $\mathrm{x}$ Age $\mathrm{x}$ Gender $)$ was found $(F(8,2524)=1.35, p<.05$, $\left.\eta_{\text {partial }}^{2}<.001\right)$.

Subsequently, univariate ANOVAs were conducted on all four subscales of the LACA in which main effects of language group, gender, and age and a Language $\mathrm{x}$ Gender interaction effect were included. Results of the main effects in these analyses are represented in Tables 5, 6, and 7. Significant main effects of language group were obtained on all four subscales of the LACA. More specifically, Dutch-speaking Belgian adolescents reported more parent-related and peer-related loneliness as well as more positive and negative attitudes toward aloneness. Regarding gender effects, univariate ANOVAs showed significant main effects of gender on positive attitudes toward aloneness and peer-related loneliness. On both subscales, girls tended to score higher. Finally, regarding age effects, late adolescents scored significantly higher than middle
Table 3 Configural invariance across language, age, and gender groups

\begin{tabular}{lllllllr}
\hline Model & $\chi^{2}$ & $d f$ & \multicolumn{1}{l}{ CFI } & \multicolumn{1}{l}{ RMSEA } & \multicolumn{1}{l}{ SRMR } & \multicolumn{1}{l}{ AIC } & \multicolumn{1}{l}{ BIC } \\
\hline Language group & & & & & & & \\
$\quad$ Dutch-speaking & $110.894 * * *$ & 48 & .983 & .045 & .036 & 9896.946 & $10,084.393$ \\
$\quad$ French-speaking & $126.984 * * *$ & 48 & .976 & .051 & .037 & $10,563.891$ & $10,751.338$ \\
Age & & & & & & & \\
$\quad$ Early adolescence & $127.702 * * *$ & 48 & .971 & .058 & .047 & 7909.461 & 8085.541 \\
$\quad$ Middle Adolescence & $105.103 * * *$ & 48 & .983 & .046 & .038 & 8540.326 & 8721.571 \\
$\quad$ Late Adolescence & $101.116 * * *$ & 48 & .963 & .068 & .048 & 3528.917 & 3674.576 \\
Gender & & & & & & & \\
$\quad$ Boys & 115.488 & 48 & .980 & .049 & .038 & 9593.623 & 9777.801 \\
$\quad$ Girls & $150.313 * * *$ & 48 & .976 & .056 & .042 & $10,572.252$ & $10,762.549$ \\
\hline
\end{tabular}

CFI Comparative fit index, RMSEA Root mean square error of approximation, SRMR Standardized root mean squared residual, AIC Akaike information criterion, BIC Bayesian information criterion

$* * * p<.001$ 
Table 4 Measurement invariance of the LACA across language groups, age, and gender (both samples combined)

\begin{tabular}{|c|c|c|c|c|c|c|c|c|c|c|}
\hline Model & $x^{2}$ & $d f$ & CFI & $\Delta \mathrm{CFI}$ & RMSEA & $\triangle \mathrm{RMSEA}$ & SRMR & $\triangle \mathrm{SRMR}$ & AIC & $\mathrm{BIC}$ \\
\hline \multicolumn{11}{|l|}{ Language } \\
\hline Configural invariance & $296.609 * * *$ & 96 & .973 & & .057 & & .044 & & $19,917.769$ & $20,350.888$ \\
\hline Metric invariance & $336.269 * * *$ & 104 & .969 & .004 & .059 & .002 & .052 & .008 & $19,945.425$ & $20,337.295$ \\
\hline Scalar invariance & $462.824 * * *$ & 112 & .953 & .016 & .070 & .011 & .053 & .001 & $20,066.277$ & $20,415.897$ \\
\hline \multicolumn{11}{|l|}{ Age } \\
\hline Configural invariance & $434.242 * * *$ & 156 & .963 & & .065 & & .058 & & $20,647.973$ & $20,060.436$ \\
\hline Metric invariance & $344.568 * * *$ & 160 & .975 & .012 & .052 & .013 & .047 & .011 & $19,959.437$ & $20,526.358$ \\
\hline Scalar invariance & $401.087 * * *$ & 176 & .970 & .005 & .055 & .003 & .048 & .001 & $20,470.213$ & $19,985.752$ \\
\hline \multicolumn{11}{|l|}{ Gender } \\
\hline Configural invariance & $265.945 * * *$ & 96 & .978 & & .053 & & .040 & & $20,641.990$ & $20,208.871$ \\
\hline Metric invariance & $277.246 * * *$ & 104 & .977 & .001 & .051 & .002 & .044 & .004 & $20,597.204$ & $20,205.334$ \\
\hline Scalar invariance & $287.227 * * *$ & 112 & .977 & .000 & .049 & .002 & .044 & .000 & $20,549.186$ & $20,198.566$ \\
\hline
\end{tabular}

CFI Comparative fit index, RMSEA Root mean square error of approximation, SRMR Standardized root mean squared residual, AIC Akaike information criterion, $B I C$ Bayesian information criterion

$* * * p<.001$

adolescents who, in turn, scored higher than early adolescents on both parent-related loneliness and positive attitudes toward aloneness. In addition, early adolescents scored significantly higher than middle adolescents on negative attitudes toward aloneness, with late adolescents scoring in between.

The previously described results have to be interpreted with caution, because a significant Language group x Gender interaction effect was found for parent-related loneliness $(F(1$, $\left.1270)=5.77, p<.05, \eta_{\text {partial }}^{2}=.01\right)$ and positive attitudes toward aloneness $\left(F(1,1270)=6.06, p<.05, \eta_{\text {partial }}^{2}=.01\right)$. These interactions indicated that Dutch-speaking adolescents reported more parent-related loneliness and more positive attitudes toward aloneness, but the difference between the language groups was more pronounced for boys than for girls.

\section{Discussion}

The present study clearly contributes to the extensive body of literature on the LACA by (a) examining the factorial validity and psychometric properties of a French version of the LACA, which was, until now, lacking, (b) investigating measurement invariance of this French version of the LACA across language, age, and gender groups, and (c) investigating possible differences in loneliness and attitudes toward aloneness between adolescents from the two main linguistic communities in Belgium, that is, the French- and Dutchspeaking communities, and Belgian adolescents from different age and gender groups.

Confirmatory factor analyses indicated that the supposed four-factor structure of the LACA fitted the data well and showed a superior fit compared to the model fit of alternative, more parsimonious models. A similar approach has been used to test the dimensionality of the Dutch version of the LACA with the same results (Maes et al., 2015b). In addition, results regarding the intercorrelations among the subscales and the reliability of the subscales are in line with a meta-analysis on the reliability of the LACA (Maes et al. 2015b). Because we found the expected factor structure of the LACA in the test scores of the French sample, we are more certain that the two

Table 5 Mean scores by language group

\begin{tabular}{|c|c|c|c|c|c|c|c|c|}
\hline \multirow[t]{3}{*}{ Subscale } & \multicolumn{8}{|c|}{ Language group } \\
\hline & \multicolumn{3}{|l|}{ Dutch group } & \multicolumn{3}{|l|}{ French group } & \multirow[t]{2}{*}{$F(1,1270)$} & \multirow[t]{2}{*}{$\eta_{p}^{2}$} \\
\hline & Mean $(S D)$ & $S E$ & $95 \% \mathrm{CI}$ & Mean $(S D)$ & $S E$ & $95 \% \mathrm{CI}$ & & \\
\hline Peer-related loneliness & $21.17(7.11)$ & 0.27 & $20.64-21.71$ & $19.04(6.63)$ & 0.27 & $18.50-19.56$ & $31.46^{* * *}$ & .02 \\
\hline Parent-related loneliness & $20.53(6.80)$ & 0.25 & $20.03-21.03$ & $18.70(5.99)$ & 0.25 & $18.20-19.19$ & $29.28 * * *$ & .02 \\
\hline Positive attitude toward aloneness & $31.15(6.32)$ & 0.26 & $30.65-31.66$ & $29.77(6.66)$ & 0.26 & $29.25-30.26$ & $16.32 * * *$ & .01 \\
\hline Negative attitude toward aloneness & $31.72(5.81)$ & 0.24 & $31.26-32.19$ & $29.00(6.25)$ & 0.24 & $28.52-29.46$ & $64.34 * * *$ & .05 \\
\hline
\end{tabular}

$* p<.05 . * * p<.01 . * * * p<.001$ 
Table 6 Mean scores by gender (both samples combined)

\begin{tabular}{|c|c|c|c|c|c|c|c|c|}
\hline \multirow[t]{3}{*}{ Subscale } & \multicolumn{8}{|l|}{ Gender } \\
\hline & \multicolumn{3}{|l|}{ Girls } & \multicolumn{3}{|l|}{ Boys } & \multirow[t]{2}{*}{$F(1,1270)$} & \multirow[t]{2}{*}{$\eta_{\mathrm{r}}^{2}$} \\
\hline & Mean $(S D)$ & $S E$ & $95 \% \mathrm{CI}$ & Mean $(S D)$ & $S E$ & $95 \% \mathrm{CI}$ & & \\
\hline Peer-related loneliness & $20.58(7.13)$ & 0.27 & $20.06-21.09$ & $19.57(6.71)$ & 0.29 & $19.01-20.13$ & $6.77 * *$ & .01 \\
\hline Parent-related loneliness & $19.60(6.40)$ & 0.25 & $19.11-20.08$ & $19.64(6.56)$ & 0.27 & $19.12-20.16$ & 0.02 & .00 \\
\hline Positive attitude toward aloneness & $30.96(6.47)$ & 0.25 & $30.46-31.43$ & $29.89(6.54)$ & 0.27 & $29.36-30.41$ & $8.69 * *$ & .01 \\
\hline Negative attitude toward aloneness & $30.68(6.17)$ & 0.24 & $30.20-31.12$ & $30.01(6.18)$ & 0.25 & $29.51-30.51$ & 3.72 & .00 \\
\hline
\end{tabular}

$* p<.05 . * * p<.01 . * * * p<.001$

types of loneliness and attitudes toward aloneness that are assessed with the French version of the LACA are the actual constructs intended by the developers of the scale (Piedmont 2014). Given the good factorial validity and reliability, we consider this French version of the LACA an appropriate measure to assess loneliness and attitudes toward aloneness in French-speaking adolescents. By establishing this French version of the LACA, in addition to the already existing Dutch version, loneliness and attitudes toward aloneness can be assessed in the two principal language groups in Belgium. This brings us one step closer to investigating possible differences in loneliness and attitudes toward aloneness across Belgium's principal language groups and, if these differences appear to be non-existent, to drawing conclusions about loneliness and attitudes toward aloneness in Belgian adolescents as a whole.

However, prior to comparing group means, it is important to make sure that an instrument measures the intended concept or concepts in the same way across the different groups (Kim and Yoon 2011). By means of measurement invariance analyses, previous research had already shown that Dutchspeaking adolescent boys and girls, and Dutch-speaking participants from different age groups across adolescence interpret the items of the LACA in a similar way (Maes et al., 2015a). However, until now, it was unknown whether Dutch-speaking and French-speaking Belgian adolescents interpret the items of the LACA in a similar way and whether
Belgian adolescents in general (i.e., both Dutch-speaking and French-speaking) from different age and gender groups interpret the items of the LACA similarly. Therefore, in this study, measurement invariance analyses across language groups, and across age and gender in the combined Belgian sample, were conducted. By means of multigroup confirmatory factor analyses, configural, metric, and scalar measurement invariance were established for the different language, age, and gender groups. This means that the LACA measures the same constructs with the same structure in all of the investigated groups. In other words, the items of the LACA and the underlying latent factors are being interpreted in a similar way by Belgian adolescents from different language groups, genders, and ages. Consequently, valid comparisons can be made on the various subscales across all of the language, age, and gender groups (van de Schoot et al. 2012).

Concerning the language group differences, results show that Dutch-speaking Belgian adolescents report more loneliness and more pronounced attitudes toward aloneness than French-speaking Belgian adolescents. These results are not in line with earlier studies about regional differences in Belgium regarding other internalizing problems, which indicated that people from the French-speaking part of Belgium report more internalizing problems (Ansseau et al. 2005, 2008). However, given the small effect sizes for the language group differences in this study (i.e., accounting for 5\% of the variance or less), caution is warranted when interpreting these

Table 7 Mean scores by age group (both samples combined)

\begin{tabular}{|c|c|c|c|c|c|c|c|c|c|c|c|}
\hline \multirow[t]{2}{*}{ Subscale } & \multicolumn{3}{|c|}{ Early adolescence } & \multicolumn{3}{|c|}{ Middle adolescence } & \multicolumn{3}{|c|}{ Late adolescence } & \multirow[t]{2}{*}{$F(2,1270)$} & \multirow[t]{2}{*}{$\eta_{r}^{2}$} \\
\hline & Mean $(S D)$ & $S E$ & $95 \% \mathrm{CI}$ & Mean $(S D)$ & $S E$ & $95 \% \mathrm{CI}$ & Mean $(S D)$ & $S E$ & $95 \% \mathrm{CI}$ & & \\
\hline Peer & $20.63(7.55)^{\mathrm{a}}$ & 0.31 & $20.00-21.23$ & $19.77(6.80)^{\mathrm{a}}$ & 0.30 & $19.19-20.35$ & $19.84(6.23)^{\mathrm{a}}$ & 0.45 & $18.95-20.72$ & 2.22 & .00 \\
\hline Parent & $17.92(5.79)^{\mathrm{a}}$ & 0.29 & $17.35-18.46$ & $20.12(6.42)^{\mathrm{b}}$ & 0.27 & $19.60-20.65$ & $21.96(6.99)^{\mathrm{c}}$ & 0.41 & $21.15-22.76$ & $36.71 * * *$ & .06 \\
\hline Positive & $29.53(6.63)^{\mathrm{a}}$ & 0.29 & $28.93-30.07$ & $30.46(6.56)^{\mathrm{b}}$ & 0.27 & 29.94-31.02 & $32.38(5.76)^{\mathrm{c}}$ & 0.42 & $31.56-33.21$ & $15.86 * * *$ & .02 \\
\hline Negative & $30.97(6.03)^{\mathrm{a}}$ & 0.28 & $30.41-31.51$ & $29.92(6.35)^{\mathrm{b}}$ & 0.26 & $29.41-30.43$ & $30.18(6.00)^{\mathrm{a}, \mathrm{b}}$ & 0.40 & $29.40-30.97$ & $4.01 *$ & .01 \\
\hline
\end{tabular}

Peers peer-related loneliness, Parent parent-related loneliness, Positive positive attitude toward aloneness, Negative negative attitude toward aloneness. Means are significantly different from one another if they have different superscripts.

$* p<.05 . * * p<.01 . * * * p<.001$ 
language group differences. More specifically, the practical relevance of these findings is probably limited. Given that this is the first study that investigated regional differences in loneliness and attitudes toward aloneness in Belgium replication research is clearly needed to further investigate these language group differences.

The findings further suggest an increase in parent-related loneliness and positive attitudes toward aloneness and a decrease in negative attitudes toward aloneness, which are in line with theoretical notions (Marcoen and Goossens 1993) and confirm our hypotheses. These main age effects do not differ in the different language groups. Therefore, we can consider these age differences as general trends that are applicable to a wider group of Belgian adolescents regardless of the language group they belong to. In addition, in contrast to our hypothesis, no decrease in peer-related loneliness was found. Regarding these age effects, it is again important to note that the effect sizes were very small, which suggests the practical relevance of these results are limited.

In line with a meta-analysis on gender differences in loneliness across the lifespan (Maes 2016), we expected no gender differences in parent- and peer-related loneliness. Our results showed that boys reported more parent-related loneliness than girls, but this difference was not statistically significant. For peer-related loneliness a significant effect was found, which indicated that girls report more peer-related loneliness. However, because only $1 \%$ of the variance in peer-related loneliness is explained by gender, we believe that the large sample size is responsible for the significant gender effect and we therefore doubt the practical relevance of the effect. Because there was a lot of inconsistency in the current literature regarding possible gender differences in positive and negative attitudes toward aloneness, we did not put forward specific hypotheses. Results showed that girls reported a more negative attitude toward aloneness than boys, but this difference was not statistically significant. Regarding positive attitude toward aloneness, girls report a more positive attitude toward aloneness than boys. However, the effect size was again very small (i.e., $1 \%$ of the variance in positive attitude toward aloneness is explained by gender), which again raises questions about the practical relevance of the effect.

Finally, significant Language group x Gender interactions indicated that there is a larger difference between adolescent boys from the different language groups than for adolescent girls regarding parent-related loneliness and positive attitude toward aloneness. However, the effect sizes associated with these Language group x Gender interactions were again very small (i.e., $1 \%$ of the variance in parent-related loneliness and positive attitude toward aloneness is explained by the interaction) which leads us to question the practical relevance of these effects. For this reason, we will not further elaborate on these findings.

\section{Limitations}

The present study has some clear strengths, such as its relatively large samples that were carefully matched in order to control for potential confounding variables and its strong methodological approach. Despite these strengths, this study also has some limitations that are important to mention and that can offer suggestions for future research.

A first limitation concerns the cross-sectional design of the study. A longitudinal study using latent growth curve analyses would provide less biased information on age trends in adolescent loneliness and attitudes toward aloneness by ruling out possible cohort effects.

A second limitation concerns the composition of the samples. Participants from the French-speaking sample all attended school in Brussels, the capital city of Belgium, which is a bilingual region. Adolescents from Wallonia, that is, the region in Belgium where people speak French exclusively, were not represented in the French-speaking sample. Therefore, results of this study cannot be generalized to the whole French-speaking community in Belgium. In addition, we only included adolescents from the academic track in our study. Although most students in the different regions of Belgium follow the academic track, a substantive number of students also follow the technical or vocational track. Given that there might be differences between adolescents from the different educational tracks regarding loneliness and attitudes toward aloneness, we cannot generalize our findings to the general population of Belgian secondary school students (See Online Resource 1 for more information). Moreover, in the Dutch-speaking sample, no background information about the participants was available. Due to this lack of information, the results obtained could be biased by confounding variables that we are not aware of.

Third, it is important to acknowledge that there is a time gap ranging from 13 to 23 years between data collection for the Dutch-speaking sample and the French-speaking sample. Because several societal changes took place during this time frame that might have impacted on feelings of loneliness and attitudes toward aloneness (e.g., an increase in the use of internet and social media), we cannot rule out the existence of confounding cohort effects (See Online Resource 2 for more detailed information).

Fourth, it is important to keep in mind that there are subtle language differences between the French spoken in Brussels and Wallonia, on the one hand, and the French spoken in other countries. As a result, caution is warranted when using this French version of the LACA with French-speaking adolescents that do not live in Belgium. Future research could, for example, examine whether the items of the French version of the LACA are interpreted in a similar way by French-speaking adolescents from different countries by means of measurement invariance analyses. 


\section{Conclusion}

By establishing a French version of the LACA, the current study filled an important gap in the literature on the LACA. Based on the results of this study, we can conclude that the French adaptation of the LACA is appropriate to assess loneliness and attitudes towards aloneness in French-speaking adolescents in Belgium. In addition, the results of this study indicate that one can validly compare mean scores of the different subscales of the LACA across Belgian adolescents from different language, gender, and age groups.

\section{Compliance with Ethical Standards}

Informed Consent Informed consent was obtained from all individual participants included in the study.

Conflict of Interest Sofie Danneel, Marlies Maes, Patricia Bijttebier, Marianne Rotsaert, Marie Delhaye, Tara Berenbaum, Luc Goossens declare that they have no conflict of interest.

Experiment Participants This article does not contain any studies with animals performed by any of the authors. All procedures performed in studies involving human participants were in accordance with the ethical standards of the institutional and/or national research committee and with the 1964 Helsinki declaration and its later amendments or comparable ethical standards.

\section{Appendix}

\section{Échelle de Solitude de Louvain pour Enfants et Adolescents LLCA-FR}

\section{Moi et les autres}

Sur les pages suivantes, vous trouverez un nombre de déclarations. Veuillez indiquer dans quelle mesure ces déclarations s'appliquent à vous (jamais, rarement, parfois ou souvent) en encerclant le numéro correspondant.

1 Jamais

2 Rarement

3 Parfois

4 Souvent

\begin{tabular}{|c|c|c|c|}
\hline 1. & Je me sens très à lié(e) à mes parents. $(\mathrm{R})$ & & \\
\hline 1 & 2 & 3 & 4 \\
\hline 2. & Je me retire pour faire des choses qui ne peuvent être faites quand on est nombreux. & & \\
\hline 1 & 2 & 3 & 4 \\
\hline 3. & Mes parents prennent le temps de s'occuper de moi. (R) & & \\
\hline 1 & 2 & 3 & 4 \\
\hline 4. & Je pense que j'ai moins d'ami(e)s que les autres. & & \\
\hline 1 & 2 & 3 & 4 \\
\hline 5. & Je me sens isolé(e) des autres. & & \\
\hline 1 & 2 & 3 & 4 \\
\hline 6. & Je veux être seul(e). & & \\
\hline 1 & 2 & 3 & 4 \\
\hline 7. & Je me sens exclu(e) par mes camarades de classe. & & \\
\hline 1 & 2 & 3 & 4 \\
\hline 8. & Quand je suis tout(e) seul(e), je m'ennuie. & & \\
\hline 1 & 2 & 3 & 4 \\
\hline 9. & Je veux être davantage intégré(e) à ma classe. & & \\
\hline 1 & 2 & 3 & 4 \\
\hline 10. & Quand je suis seul(e), je me sens mal. & & \\
\hline 1 & 2 & 3 & 4 \\
\hline 11. & Je me sens mis(e) de côté par mes parents. & & \\
\hline 1 & 2 & 3 & 4 \\
\hline 12. & Quand je me sens seul(e), je vais voir mes ami(e)s. & & \\
\hline 1 & 2 & 3 & 4 \\
\hline 13. & Je cherche un moment pour être seul(e) pour réfléchir. & & \\
\hline 1 & 2 & 3 & 4 \\
\hline 14. & Quand je m'ennuie, je suis malheureux(se). & & \\
\hline
\end{tabular}


(continued)

\begin{tabular}{|c|c|c|c|}
\hline 1 & 2 & 3 & 4 \\
\hline 15. & J'ai du mal à me faire des ami(e)s. & & \\
\hline 1 & 2 & 3 & 4 \\
\hline 16. & Je trouve du réconfort auprès de mes parents. $(\mathrm{R})$ & & \\
\hline 1 & 2 & 3 & 4 \\
\hline 17. & J'ai peur que les autres ne me laissent pas m'intégrer. & & \\
\hline 1 & 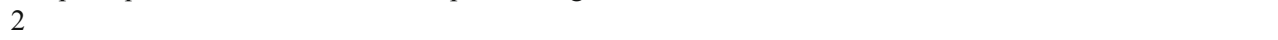 & 3 & 4 \\
\hline 18. & Je trouve qu'il est difficile de parler avec mes parents. & & \\
\hline 1 & 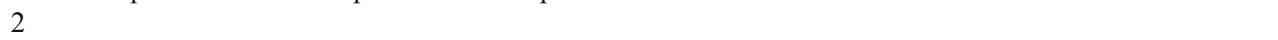 & 3 & 4 \\
\hline 19. & Quand je me sens isolé(e), je veux être seul(e) pour y réfléchir. & & \\
\hline 1 & 2 & 3 & 4 \\
\hline 20. & Quand je me sens seul(e), je ne sais pas quoi faire. & & \\
\hline 1 & 2 & 3 & 4 \\
\hline 21. & Quand j'ai une dispute avec quelqu'un, je veux être seul(e) pour y réfléchir. & & \\
\hline 1 & 2 & 3 & 4 \\
\hline 22. & Pour m'amuser réellement j'ai besoin d'être avec mes ami(e)s. & & \\
\hline 1 & 2 & 3 & 4 \\
\hline 23. & Je me sens seul(e) à l'école. & & \\
\hline 1 & 2 & 3 & 4 \\
\hline 24. & Quand je suis seul(e), le temps dure une éternité et aucune activité ne m'attire. & & \\
\hline 1 & 2 & 3 & 4 \\
\hline 25. & Je peux bien m'entendre avec mes parents. (R) & & \\
\hline 1 & 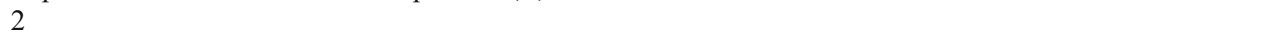 & 3 & 4 \\
\hline 26. & Quand je suis seul(e), je me calme. & & \\
\hline 1 & 2 & 3 & 4 \\
\hline 27. & Je pense que je n'ai aucun(e) ami(e) à qui je peux tout raconter. & & \\
\hline 1 & 2 & 3 & 4 \\
\hline 28. & Pour penser à quelque chose sans être dérangé(e), j'ai besoin d'être seul(e). & & \\
\hline 1 & 2 & 3 & 4 \\
\hline 29. & Quand je suis seul(e), j'aimerais avoir d'autres personnes autour de moi. & & \\
\hline 1 & 2 & 3 & 4 \\
\hline 30. & Mes parents sont prêts à m'écouter et à m'aider. (R) & & \\
\hline 1 & 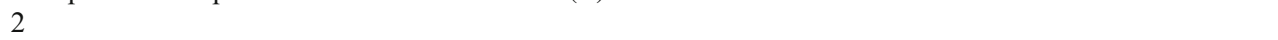 & 3 & 4 \\
\hline 31. & Je suis content(e) quand je suis seul(e) à la maison parce que ça me donne l'occasion de réfléchir calmement. & & \\
\hline 1 & 2 & 3 & 4 \\
\hline 32. & Quand je m'ennuie, je vais voir un(e) ami(e). & & \\
\hline 1 & 2 & 3 & 4 \\
\hline 33. & Je me sens abandonnée par mes ami(e)s. & & \\
\hline 1 & 2 & 3 & 4 \\
\hline 34. & Je me sens malheureux(se) quand je dois faire les choses seul(e). & & \\
\hline 1 & 2 & 3 & 4 \\
\hline 35. & Je me sens laissé(e) de côté par mes ami(e)s. & & \\
\hline 1 & 2 & 3 & 4 \\
\hline 36. & Je veux être seul(e) pour faire certaines choses. & & \\
\hline 1 & 2 & 3 & 4 \\
\hline 37. & J'ai le sentiment d'avoir ma place auprès de mes parents. (R) & & \\
\hline 1 & 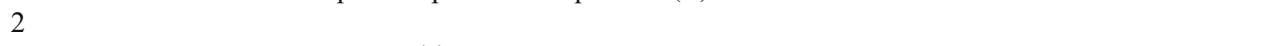 & 3 & 4 \\
\hline 38. & Mes parents partagent mes centres d'intérêt. (R) & & \\
\hline 1 & 2 & 3 & 4 \\
\hline 39. & Quand je me sens seul(e), je vais voir d'autres personnes. & & \\
\hline 1 & 2 & 3 & 4 \\
\hline 40. & Je reste à l'écart des autres parce qu'ils me dérangent avec leurs bruits. & & \\
\hline 1 & 2 & 3 & 4 \\
\hline 41. & Je me sens triste parce que personne ne veut se joindre à moi. & & \\
\hline 1 & 2 & 3 & 4 \\
\hline 42. & Quand je m'ennuie, je me sens seul(e). & & \\
\hline 1 & 2 & 3 & 4 \\
\hline 43. & Mes parents me montrent beaucoup d'intérêt. (R) & & \\
\hline 1 & 2 & 3 & 4 \\
\hline 44. & Être seul(e) me permet de reprendre courage. & & \\
\hline 1 & 2 & 3 & 4 \\
\hline 45. & J'ai l'impression que mes parents ne m'aiment pas vraiment. & & \\
\hline 1 & 2 & 3 & 4 \\
\hline
\end{tabular}

46. À la maison, je cherche des moments pour être seule pour faire des choses tout(e) seul(e). 
(continued)

\begin{tabular}{llc}
\hline 1 & 2 & 3 \\
47. & Je suis triste parce que je n'ai pas d'ami(e)s. & 4 \\
1 & 2 & 3 \\
48. & À la maison, je me sens à l'aise. (R) & 4 \\
1 & 2 & 4 \\
\hline
\end{tabular}

Note. $\mathrm{R}$ indique que le score doit être inversé

\section{References}

Ansseau, M., Fischler, B., Dierick, M., Mignon, A., \& Leyman, S. (2005). Prevalence and impact of generalized anxiety and major depression in primary care in Belgium and Luxemburg: the GADIS study. European Psychiatry, 20, 229-235. https://doi.org/ 10.1016/j.europsy.2004.09.035.

Ansseau, M., Fischler, B., Dierick, M., Albert, A., Leyman, S., \& Mignon, A. (2008). Socio- economic correlates of generalized anxiety and major depression in primary care: the GADIS II study (generalized anxiety and depression impact survey II). Depression and Anxiety, 25, 506-513. https://doi.org/10.1002/da.20306.

Barrett, P. (2007). Structural equation modelling: adjudging model fit. Personality and Individual Differences, 42, 815-824. https://doi. org/10.1016/j.paid.2006.09.018.

Baumeister, R. F., \& Leary, M. R. (1995). The need to belong: desire for interpersonal attachments as a fundamental human motivation. Psychological Bulletin, 117, 497-529. https://doi.org/10.1037/ 0033-2909.117.3.497.

Benjamini, Y., \& Hochberg, Y. (1995). Controlling the false discovery rate: a practical and powerful approach to multiple testing. Journal of the Royal Statistical Society. Series B-Methodological, 57, 289300.

Boomsma, A. (2000). Reporting analyses of covariance structures. Structural Equation Modeling: A Multidisciplinary Journal, 7, 461-483. https://doi.org/10.1207/S15328007SEM0703_6.

Cacioppo, J. T., Hawkley, L. C., Ernst, J. M., Burleson, M., Bertson, G. G., Nouriani, B., \& Spiegel, D. (2006). Loneliness within a nomological net: an evolutionary perspective. Journal of Research in Personality, 40, 1054-1085. https://doi.org/10.1016/j.jrp.2005.11. 007.

Chen, F. F. (2007). Sensitivity of goodness of fit indexes to lack of measurement invariance. Structural Equation Modeling: A Multidisciplinary Journal, 14, 464-504. https://doi.org/10.1080/ 10705510701301834.

Clark-Lempers, D. S., Lempers, J. D., \& Ho, C. (1991). Early, middle, and late adolescents' perceptions of their relationships with significant others. Journal of Adolescent Research, 6, 296-315. https://doi. org/10.1177/074355489163003.

Cohen, J. (1988). Statistical power analysis for the behavioral sciences (2nd ed.). Hillsdale: Erlbaum.

Corsano, P., Majorano, M. L., \& Champretavy, C. (2006). Psychological well-being in adolescence: the contribution of interpersonal relations and experience of being alone. Adolescence, 41, 341-353.

De Vellis, R. F. (2003). Scale development: theory and applications (2nd ed.). Thousand Oaks: Sage.

European Commission (2005). Europeans and languages: Eurobarometer 63.4. Retrieved from http://ec.europa.eu/public opinion/archives/ebs/ebs_237.en.pdf

Furukawa, R., Driessnack, M., \& Colclough, Y. (2014). A committee approach maintaining cultural originality in translation. Applied Nursing Research, 27, 144-146. https://doi.org/10.1016/j.apnr. 2013.11.01.

Goossens, L. (Ed.). (2016). Leuvense Eenzaamheidsschaal voor Kinderen en Adolescenten: Handleiding [Loneliness and
Aloneness Scale for Children and Adolescents: Manual]. Leuven: Acco.

Goossens, L., \& Marcoen, A. (1999). Relationships during adolescence: constructive vs. negative themes and relational dissatisfaction. Journal of Adolescence, 22, 65-79. https://doi.org/10.1005/jado. 1998.0201.

Goossens, L., Lasgaard, M., Luyckx, K., Vanhalst, J., Mathias, S., \& Masy, E. (2009). Loneliness and solitude in adolescence: a confirmatory factor analysis of alternative models. Personality and Individual Differences, 47, 890-894. https://doi.org/10.1016/j.paid. 2009.07.011.

Hayduk, L., Cummings, G., Boadu, K., Pazderka-Robinson, H., \& Boulianne, S. (2007). Testing! Testing! One, two, three: testing the theory in structural equation models! Personality and Individual Differences, 42, 841-850. https://doi.org/10.1016/j.paid.2006.10. 001.

Heinrich, L. A., \& Gullone, E. (2006). The clinical significance of loneliness: a literature review. Clinical Psychology Review, 26, 695-718. https://doi.org/10.1016/j.cpr.2006.04.002.

Hu, L., \& Bentler, P. M. (1999). Cutoff criteria for fit indexes in covariance structure analysis: conventional criteria versus new alternatives. Structural Equation Modeling: A Multidisciplinary Journal, 6, 1-55. https://doi.org/10.1080/10705519909540118.

Kim, E. S., \& Yoon, M. (2011). Testing measurement invariance: a comparison of multiple- group categorical CFA and IRT. Structural Equation Modeling, 18, 212-228. https://doi.org/10.1080/ 10705511.2011.557337.

Kline, R. B. (2005). Principles and practice of structure equation modelling. New York, NY: Guilford Press.

Ladd, G. W., \& Ettekal, I. (2013). Peer-related loneliness across early to late adolescence: normative trends, intra-individual trajectories, and links with depressive symptoms. Journal of Adolescence, 36, 1269 1282. https://doi.org/10.1016/j.adolescence.2013.05.004.

Larson, R. W. (1997). The emergence of solitude as a constructive domain of experience in early adolescence. Child Development, 68, 80-93. https://doi.org/10.2307/1131927.

Larson, R., \& Richards, M. H. (1991). Daily companionship in late childhood and early adolescence: changing developmental contexts. Child Development, 62, 284-300. https://doi.org/10.2307/1131003.

Laursen, B., \& Hartl, A. C. (2013). Understanding loneliness during adolescence: developmental changes that increase the risk of perceived social isolation. Journal of Adolescence, 36, 1261-1268. https://doi.org/10.1016/j.adolescence.2013.06.003.

Little, R. J. A. (1988). A test of missing completely at random for multivariate data with missing values. Journal of the American Statistical Association, 83(404), 1198-1202.

Little, T. D., Cunningham, W. A., Shahar, G., \& Widaman, K. F. (2002). To parcel or not to parcel: exploring the question, weighing the merits. Structural Equation Modeling, 9, 151-173. https://doi.org/ 10.1207/S15328007SEM0902 1.

Long, C. R., \& Averill, J. R. (2003). Solitude: an exploration of benefits of being alone. Journal for the Theory of Social Behaviour, 33, 21 44. https://doi.org/10.1111/1468-5914.00204.

Maes, M. (2016). Loneliness in adolescence: Types of loneliness, measurement, and a meta-analytic perspective on group differences (Unpublished doctoral dissertation). KU Leuven, Leuven, Belgium. 
Maes, M., Klimstra, T., Van Den Noortgate, W., \& Goossens, L. (2015a). Factor structure and measurement invariance of a multidimensional loneliness scale: comparisons across gender and age. Journal of Child and Family Studies, 24, 1829-1837. https://doi.org/10.1007/ s10826-014-9986-4.

Maes, M., Van Den Noortgate, W., \& Goossens, L. (2015b). A reliability generalization study for a multidimensional loneliness scale: the loneliness and aloneness scale for children and adolescents. European Journal of Psychological Assessment, 31, 294-301. https://doi.org/10.1027/1015-5759/a000237.

Maes, M., Qualter, P., Vanhalst, J., Van den Noortgate, W., \& Goossens, L. (2017). Gender differences in loneliness across the lifespan: a meta-analysis. Manuscript submitted for publication.

Majorano, M., Musetti, A., Brondino, M., \& Corsano, P. (2015). Loneliness, emotional autonomy and motivation for solitary behavior during adolescence. Journal of Child and Family Studies, 24, 3436-3447. https://doi.org/10.1007/s10826-015-0145-3.

Marcoen, A., \& Goossens, L. (1993). Loneliness, attitude toward aloneness, and solitude: age differences and developmental significance during adolescence. In S. Jackson \& H. Rodriguez-Tome (Eds.), Adolescence and its social worlds (pp. 197-227). Hove: Erlbaum.

Marcoen, A., Goossens, L., \& Caes, P. (1987). Loneliness in pre through late adolescence: exploring the contributions of a multidimensional approach. Journal of Youth and Adolescence, 16, 561-577. https:// doi.org/10.1007/BF02138821.

Matsunaga, M. (2008). Item parceling in structural equation modeling: a primer. Communication Methods and Measures, 2, 260-293. https:// doi.org/10.1080/19312450802458935.

Muthén, L. K., \& Muthén, B. O. (1998-2012). Mplus user's guide (7th ed.). Los Angeles: Muthén \& Muthén.

Neath, A. A., \& Cavanaugh, J. E. (2012). The Bayesian information criterion: background, derivation, and applications. Wiley Interdisciplinary Reviews: Computational Statistics, 4, 199-203. https://doi.org/10.1002/wics.199.

Perlman, D., \& Peplau, L. A. (1981). Toward a social psychology of loneliness. In S. Duck \& R. Gilmour (Eds.), Personal relationships in disorder (Vol. 3, pp. 31-56). London: Academic Press.

Piedmont, R. L. (2014). Factorial validity. In A. C. Michalos (Ed.), Encyclopedia of quality of life and well-being research (pp. 2148-
2149). New York: Springer. https://doi.org/10.1007/978-94-0070753-5 984.

Qualter, P., Vanhalst, J., Harris, R. A., van Roekel, E., Lodder, G., Bangee, M., et al. (2015). Loneliness across the life span. Perspectives on Psychological Science, 10, 250-264. https://doi. org/10.1177/1745691615568999.

Rushton, J. P., Brainerd, C. J., \& Pressley, M. (1983). Behavioral development and construct validity: the principle of aggregation. Psychological Bulletin, 94, 18-38. https://doi.org/10.1037/00332909.94.1.18.

Satorra, A., \& Bentler, P. M. (2001). A scaled difference chi-square test statistic for moment structure analysis. Psychometrika, 66, 507-514. https://doi.org/10.1007/BF02296192.

Scharf, M., Wiseman, H., \& Farah, F. (2011). Parent-adolescent relationships and social adjustment: the case of a collectivistic culture. International Journal of Psychology, 46, 177-190. https://doi.org/ 10.1080/00207594.2010.528424.

Schumacker, R. E., \& Lomax, R. G. (2004). A beginner's guide to structural equation modeling. New Jersey: Erlbaum.

Ulman, J. B. (2013). Structural equation modeling. In B. G. Tabachnick \& L. S. Fidell (Eds.), Using multivariate statistics (6th ed., pp. 681785). Boston: Pearson Education.

van de Schoot, R., Lugtig, P., \& Hox, J. (2012). A checklist for testing measurement invariance. European Journal of Developmental Psychology, 9, 486-492. https://doi.org/10.1080/17405629.2012. 686740.

van Roekel, E., Scholte, R. H., Verhagen, M., Goossens, L., \& Engels, R. C. (2010). Loneliness in adolescence: gene x environment interactions involving the serotonin transporter gene. Journal of Child Psychology and Psychiatry, 51, 747-754. https://doi.org/10.1111/j. 1469-7610.2010.02225.x.

Vandenberg, R. J., \& Lance, C. E. (2000). A review and synthesis of the measurement invariance literature: suggestions, practices, and recommendations for organizational research. Organizational Research Methods, 3, 4-69. https://doi.org/10.1177/ 109442810031002.

World Health Organization (2014). Health for the world's adolescents: A second chance in the second decade. Retrieved from http://apps. who.int/adolescent/second-decade/ 